EPJ Web of Conferences 76, 01040 (2014)

DOI: $10.1051 /$ epjconf/20147601040

(C) Owned by the authors, published by EDP Sciences, 2014

\title{
The dynamics of a vapour bubble growth under the boiling of a subcooled liquid in low volumes
}

\author{
Evgenija Orlova, Geniy Kuznetsova, and Dmitriy Feoktistovb
}

Department of Theoretical and Industrial Heat Systems Engineering, Institute of Power Engineering, Tomsk Polytechnic University, Tomsk, Russia

\begin{abstract}
This paper presents an experimental study of the dynamics of a vapour bubble growth under the boiling of a subcooled liquid in low volumes. The influence of the mode parameters (heat flux and subcooling to the saturation temperature) on the geometric characteristics of the vapour bubble (base diameter and height) has been found.
\end{abstract}

\section{Introduction}

At present the vapour bubbles growth in the boiling process under small and moderate overheating is well studied [1-13]. However, the vaporization processes at maximum achievable superheating and subcooling of the liquid aren't still studied.

The thermal inertia diagram of the vapour bubble growth in an unlimited volume of superheated liquid [1] has been formulated. According to the experimental results [1] the vapour bubbles growth in perispinodal area has been described.

The model of vapour bubble growth in a uniformly superheated liquid [2] is known. This model includes that the evaporation in the vapor bubble is caused not only by the heat from the heating surface transferred through the liquid to the bottom of the bubble, as well as due to the energy of the superheated liquid layer at the interface.

The theory of growth of spherical bubbles in unlimited liquid and hemispherical bubbles on a heated flat surface under microgravity mode has been developed [3]. The spatial and temporal variations of temperature and velocity fields in the surrounding liquid with the bubble growth have been taken into account. The thermal and hydrodynamic dependences on a phase boundary "vapor-liquid-solid" for an isolated single bubble growing on a heated flat surface have been determined.

The simulation of the bubble growth on a heated surface at boiling saturated liquid has been performed in the two-dimensional approximation [4]. The bubble growth in this model is due to thermal diffusion. The problem of thermal conductivity for the liquid around the bubble has been solved by finite element method. It is suggested that bubble grows slowly at the high pressure. Its shape is determined by the surface tension and reaction force of a steam. The authors suppose that the bubble may form a vapor film separating the liquid from the heater, causing the departure from nucleate boiling.

This is an Open Access article distributed under the terms of the Creative Commons Attribution License 4.0, which permits unrestricted use, distribution, and reproduction in any medium, provided the original work is properly cited. 
According to the results of simulation the dependence of the diameter and height of the bubble from the heat flux has been established.

The simulation of a steam bubble oscillations during its growth on the heating surface [14] has been conducted. Results are presented as the dependence of the radius of the growing bubble from time. It is found that the process of the bubble growth is accompanied by oscillations. The range of frequencies and amplitudes at the interface has been defined.

The dynamics of periodic explosive boiling [15-17] has been studied experimentally. The method for detecting the nucleation and the bubble growth has been developed by authors. The dependences of boiling time and life cycle of the bubble from pulse repetition period of heating have been drawn up. The physical model of a heterogeneous explosive boiling of the liquid on the heater with a narrow distribution of nucleation sites at very high heat fluxes has been formulated. It has been established that the maximum size of a vapour bubble formed on the micro heater is linearly dependent on the lifetime.

Modeling representations of the boiling of the subcooled water under forced flow have been studied and also a comprehensive analysis has been conducted [18-24]. It is found that at subcooling temperatures over $50^{\circ}$ the hydraulic resistance coefficients equal under the boiling and forced convection of a single-phase liquid at non-isothermal flow. Vapour bubbles do not go beyond the viscous sub layer. Normal bubbles "evacuation" [23] from the heating wall with their going beyond the viscous sublayer is missing. Ejection phenomenon of numerous small (10-80 mm) bubbles (called "microbubble emission") at the subcooled boiling water under the high heat fluxes has been explained by releasing of the rest of air on the superheated surface and in the boundary layer of the liquid [24]. This air has not been removed by deaeration. The influence of the mode parameters (heat flux and subcooling to the saturation temperature) on the sound characteristics of the resulting vapor-air -water mixture in the boiling process in a large volume has been established [24].

Physical models of the vapour bubble growth in the volume of superheated liquid by extra enthalpy overheating [5, 6] have been formulated.

Model [7-9], in which the main evaporation zone is on the areas of the bubble surface located near its button, allows determining the growth rate of vapour bubbles.

Analytical solution for the growth rate of the fixed vapour bubbles in the superheated liquid was performed in [10]. The system of equations included the continuity equation, the radial interface motion and thermal conductivity. The breakaway size and departure frequency of vapor bubble are needed to determine the removal rate of the vapor from the heating surface. These characteristics of the vapour bubbles at subcooled boiling in small volumes have not been studied at the level which provides investigation of their behavior. The results of the impact of liquid subcooling to the saturation temperature in the range of $15{ }^{\circ} \mathrm{C}$ at small volumes $(15 \mathrm{ml})$ on the evaporation and the size of the vapour bubble have not published yet.

The nucleation and the initial stage of the steam and gas-steam bubbles growth occur close of the heating surface [11]. Small size of the boundary layer of vaporization does not allow the use of conventional methods of measurement. It is necessary to use non-contact optical methods of registration of the main parameters.

The aim of this work is to establish features of the vapour bubble growth under boiling of the subcooled liquid from $85^{\circ} \mathrm{C}$ to saturation temperature in small volumes (up to $15 \mathrm{ml}$ ).

\section{Research technique}

The shadow method has been used for investigation of the bubbles growth at the boiling process in small volumes at different temperatures of heating surfaces [25-28]. Schematic diagram of the experimental setup is shown in Fig. 1.

The cell 4 was placed on the copper plate with the electric heater 3 . Visualization system consisted of the light source 1, the condensing lens 5, nontransparent shield with a hole 6 and speed video 

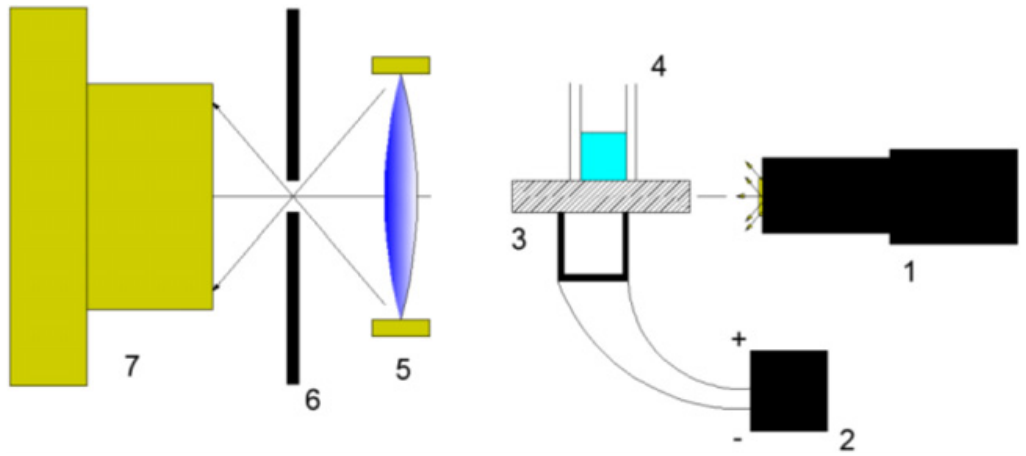

Figure 1. Schematic diagram of the experimental setup: 1 - the light source; 2 - power unit of electric heater; 3 - copper plate and electric heater; 4 - cell (rectangular shaped vessel made of glass); 5 - condensing lens; 6 nontransparent shield with a hole; 7 - camera.

camera 7. Digital Camera Fastvideo-500M with $1280 \times 1024$ resolution provided a shooting speed of 500 frames/s.

The cell 4 is a vessel of rectangular shape made of glass thickness of $2 \mathrm{~mm}$. The bottom of the cell is a smooth surface.

The heat source was a glowing filament, made in the form of an open top and bottom metal casing diameter of $50 \mathrm{~mm}$, consisting of nine turns of nichrome wire with a diameter of $2 \mathrm{~mm}$ and a length of 1 meter. The round plate with a diameter of $12 \mathrm{~mm}$ and a thickness of $5 \mathrm{~mm}$ made of copper (GOST 617-90) was placed directly on the heating element.

Measuring of the temperature of the liquid, wall and bottom of the cell was carried out using eightchannel device Agilent 34901A. As the temperature sensors 3 chromel-copel thermocouples were used. They made of wire a diameter of $0.2 \mathrm{~mm}$ (copper-nickel alloy). Thermocouples were calibrated with an accuracy of $\pm 0.1^{\circ} \mathrm{C}$.

Variable factors in the experiments: volume and temperature of the liquid, composition of the original substance. The measured characteristics of the process: temperature of the heating agent and walls of the cell, as well as the sizes of the vapour bubble (base diameter and height).

Investigations were carried out using distilled nondeaerate water, ethylene glycol-distilled nondeaerate water solution (1:1 concentration).

Heat flux to the surface of the cell was calculated from the condition of obtaining the fluid temperature in the range from 85.0 to $99.6^{\circ} \mathrm{C}$.

According to the results of preliminary experiments adopted the following range of variation of factors:

$$
\begin{aligned}
& 5 \leq X_{1} \leq 15, \mathrm{ml} \\
& 85.0 \leq X_{2} \leq 99.6,{ }^{\circ} \mathrm{C} \\
& 1.810^{5} \leq X_{3} \leq 6.810^{5}, \mathrm{~W} / \mathrm{m}^{2}
\end{aligned}
$$

where $X_{1}, X_{2}, X_{3}$ - the volume of original liquid, the temperature of liquid and the specific heat flux. Varying intervals:

$$
\begin{gathered}
\Delta X_{1}=5 \mathrm{ml}, \\
\Delta X_{2}=5^{\circ} \mathrm{C}, \\
X_{3}=\left[1.810^{5} ; 3,410^{5} ; 5,110^{5} ; 6,810^{5}\right] \mathrm{W} / \mathrm{m}^{2} .
\end{gathered}
$$




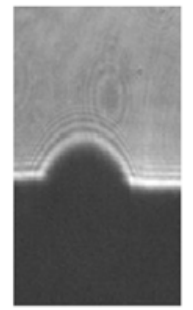

a)

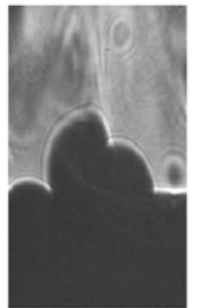

b)

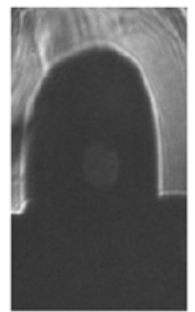

c)

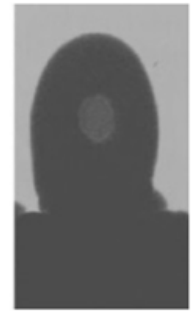

d)

Figure 2. Relative stages of the evaporation process: a) the nucleation of a bubble; b) the interaction of the vapor bubble with each other; c) the growth of the bubble; d) separation of the vapour bubble.

In order to minimize random errors in research constant external conditions has been provided. The initial temperature of the original mixture was maintained constant. All experiments were performed at ambient temperatures $293 \ldots 298 \mathrm{~K}\left(20 \ldots 25^{\circ} \mathrm{C}\right)$.

When using a single cell in the experiments the permanent centers of vaporization (distribution of nucleation sites was of a random nature) were not installed. In this regard, the area of the surface was marked on the bottom of the cell and in a sequential series of experiments the diameter and height of the vapour bubble were recorded.

\section{Results and discussion}

According to the analysis of video recordings it was established that during the initial period of heating the original liquid is stationary. In the following, there is a chaotic molecular movement in volume. During the heating of the distilled nondeaerate water the water waves motion in the cell was registered. Rotational motion was registered in the ethylene glycol solution.

It should be noted that recorded in the experiments evolution stages of the vapour bubble under the boiling of subcooled liquid in a small volume under atmospheric conditions conform to the identified changes of the geometric characteristics of the bubble under the overheating and underheating in a large volumes $[7,8]$. Thus, at the initial period the molecular movement of the liquid and the nucleation of bubbles on the heating surface took place (Fig. 2a). The next stage is the interaction of steam formations and their junction into one larger bubble (Fig. 2b). The third stage was characterized by the growth of the bubble, a deviation from the original spherical shape, pulling away from the surface (Fig. 2c). The final stage was the separation of the vapor bubble from the heating surface and its destruction in the liquid volume or on the surface (Fig. 2d). The feature of the evolution of a vapour bubble at the boiling of subcooled liquid in a small volume was the reduction of the base diameter on the separation stage.

It is known [12] that the vapour bubble growth is accompanied by simultaneous processes of evaporation and condensation. It can be assumed that the maximum base diameter of the bubble at subcooling to the saturation temperature $0-15^{\circ} \mathrm{C}$ is reached at equality between the amound of evaporating liquid and condensable vapor inside the bubble. Reducing the diameter of the bubble is probably due to the predominance of condensation over evaporation.

At variation of the volume of liquid from 5 to $15 \mathrm{ml}$ the evolution stages of a vapour bubble are similar. The difference in the recorded values of the base diameter and height of the bubbles in the identical stages is not more than $\pm 10 \%$, which is comparable with the error of the research.

Figure 3 shows the dependence of the base diameter of a vapor bubble under the liquid subcooling from $85^{\circ} \mathrm{C}$ to the saturation temperature. The beginning of the registration of the base diameter bubble was conducted with the third stage. 


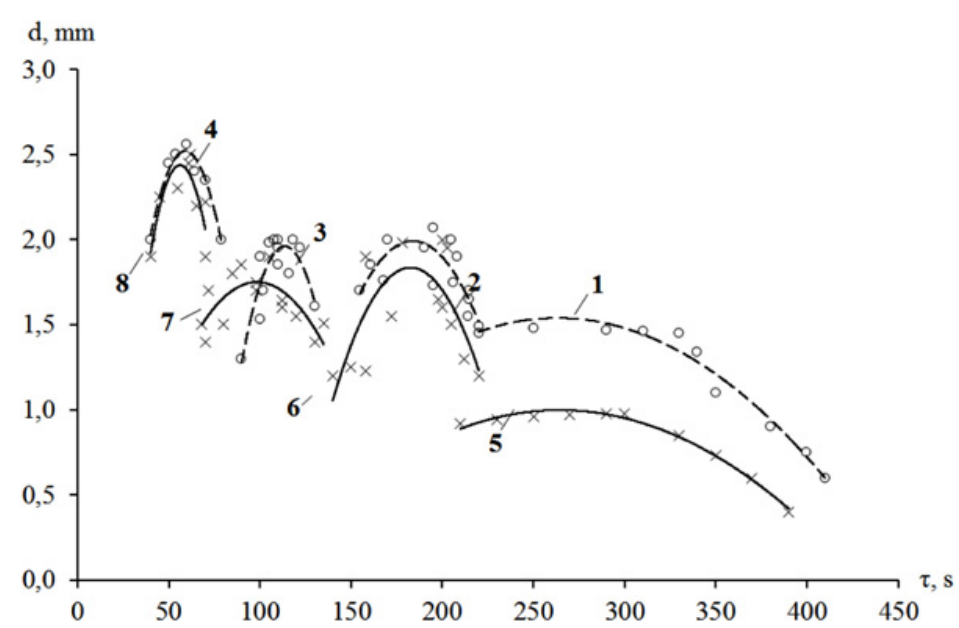

Figure 3. The dependence of the base diameter of the vapour bubble from time: 1, 2, 3, 4 - distilled water; $5,6,7,8-50 \%$ ethylene-glycol solution. 1,5 - subcooling temperature $15^{\circ} \mathrm{C}, q=1.8 \cdot 10^{5} \mathrm{~W} / \mathrm{m}^{2} ; 2,6-$ subcooling temperature $10^{\circ} \mathrm{C}, q=3.4 \cdot 10^{5} \mathrm{~W} / \mathrm{m}^{2} ; 3,7-$ subcooling temperature $5{ }^{\circ} \mathrm{C}, q=5.1 \cdot 10^{5} \mathrm{~W} / \mathrm{m}$; $4,8-q=1.8 \cdot 10^{5} \mathrm{~W} / \mathrm{m}^{2}$.

It is found that with the increasing of the specific heat flux from $1.8 \cdot 10^{5}$ to $6.8 \cdot 10^{5} \mathrm{~W} / \mathrm{m}^{2}$ (decreasing of subcooling from $85^{\circ} \mathrm{C}$ to saturation temperature), the maximum base diameter of the vapour bubble increased from $1.614 \mathrm{~mm}$ up to $2.834 \mathrm{~mm}$ for distilled water and from $1.278 \mathrm{~mm}$ to $2.543 \mathrm{~mm}$ for ethilene-glycol. During the vapor bubble formation it is influenced by a group of forces: inertial, lifting, surface tension and resistance [5, 13]. Due to the fact that in similar experimental conditions using nondeaerate distilled water and ethilene-glycol solution thermal and hydrodynamic parameters were held constant, accounting of the influence of the inertia forces, the lifting forces and resistance to the formation of the geometric dimensions of the steam formations can be considered approximately equal. Therefore, it can be assumed that the main force that affects the diameter and height of the bubble under identical boiling conditions, but the various liquid composition is a surface tension of the heating agent. Consequently, the higher the surface tension of the fluid, the larger the diameter of a vapor bubble under the liquid subcooling to saturation temperature in small volumes.

It is found that with increasing of the heat flux (flow temperature) "lifetime" of steam formations decreases (Fig. 3). This effect is due to the higher intensity of the evaporation of the liquid surrounding the vapor bubble.

Figures 4, 5 shows the effect of the heat flux density on the characteristic dimensions of the bubble (the maximum height and the base diameter) at the time of separation from the heating surface under the subcooling from $15^{\circ} \mathrm{C}$ to the saturation temperature.

It is established that with increasing of the energy flux the maximum base diameter of the vapour bubble in distilled water at the time of separation increases and lays in the range from $0.8 \mathrm{~mm}$ to $2.5 \mathrm{~mm}$. The maximum value of diameter is achieved at a saturation temperature of $99.6^{\circ} \mathrm{C}$ and takes values ranging from $2.100 \mathrm{~mm}$ to $2.428 \mathrm{~mm}$. In turn, the height of the steam bubble decreases with the increasing of the energy flux and the interval of values ranging from $2.5 \mathrm{~mm}$ to $3.8 \mathrm{~mm}$.

Similar dynamics of the bubble growth was registered at the boiling of ethylene-glycol solution. In this case, the maximum base diameter of the vapour bubble has values in the range of 0.456 to $2.403 \mathrm{~mm}$ and a height of 2.468 to $3.523 \mathrm{~mm}$ (Figs. 4, 5).

It is established that during the boiling of subcooled liquid in a small volume at atmospheric conditions the typical dimensions of the steam formations of ethylene-glycol solution less than 


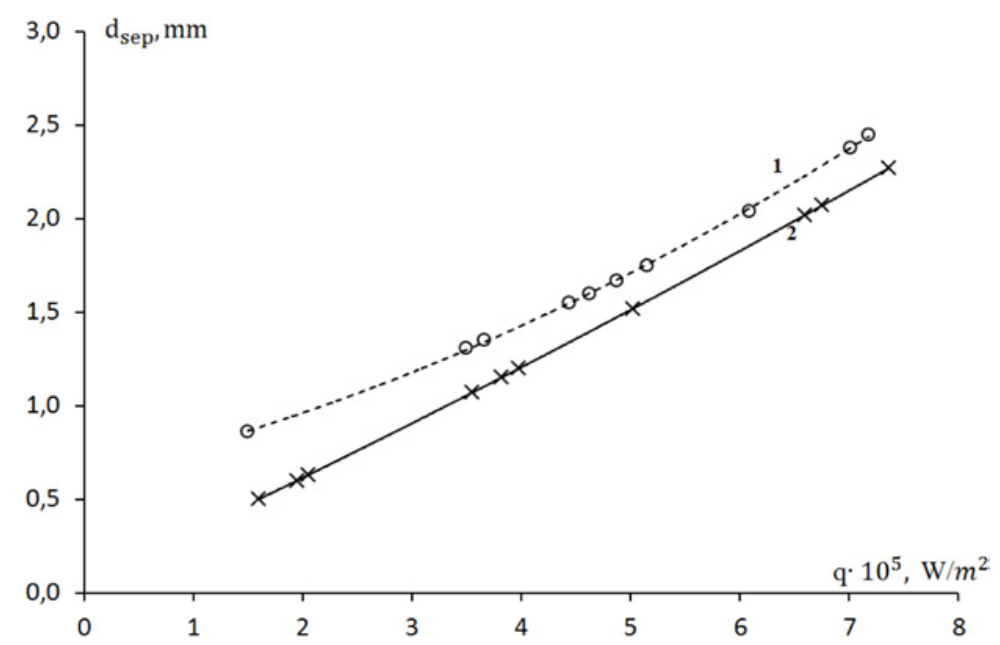

Figure 4. The dependence of the base diameter of the vapour bubble at the time of separation from the specific heat flux: 1 - distilled water; $2-50 \%$ ethylene-glycol solution.

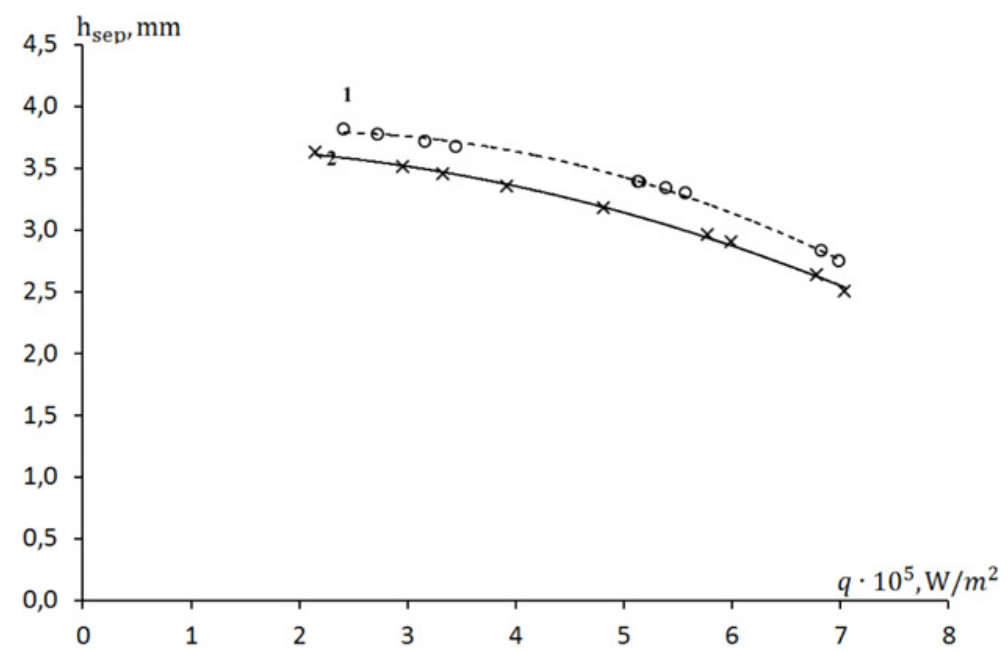

Figure 5. The dependence of the height of the vapour bubble at the moment of separation from the specific heat flux: 1-distilled water; $2-50 \%$ ethylene-glycol solution.

distilled water. It can be assumed that this fact is affected by the surface tension of the liquid. Thus, with its decreasing the geometric characteristics of the vapour bubbles are reduced.

It is found that at the boiling in small volumes $(15 \mathrm{ml})$ decreasing of the subcooling temperature affects the dynamics of steam formation in the following manner: the height of the vapour bubble reduces, the base diameter increases. It can be assumed that this is due to the fact that the condensation process is intensified inside evaporation, and the role of evaporation decreases.

\section{Conclusion}

The visualization of boiling of distilled nondeaerate water and ethylene-glycol solution in small volumes $(15 \mathrm{ml})$ at subcooling from $15^{\circ} \mathrm{C}$ to the saturation temperature was carried out during the experiments. 
Experiments have to clarify the dynamics of the vapour bubble growth, which will contribute to the development of the theory of subcooled boiling.

\section{References}

[1] A.A. Avdeev, Yu.B. Zudin, High Temp+ 40 (6), 971 (2002)

[2] V.V. Jagow V, Proceedings of the 3d Russian National Conference of Heat Transfer, Moscow, Russia, 2002 (MEI, Moscow, 2002), p. 203

[3] A.J. Robinson, R.L. Judd, Int. J. Heat Mass Transfer 44 (14), 2699 (2001)

[4] V.S. Nikolayev, D.A. Beysens, G.-L. Lagier, J. Hegseth, Int. J. Heat Mass Transfer 44 (18), 3499 (2001)

[5] V. Fritz, V. Endo, Questions of the physics of boiling, pp. 162-188 (Mir, Moscow, 1964) [in Russian]

[6] G. Forester, N. Zubr, Questions of the physics of boiling, pp. 212-225 (Mir, Moscow, 1964) [in Russian]

[7] D.A. Labuntsov, Journal of Engineering Physics and Thermophysics 6 (4), 33 (1963)

[8] D.A. Labuntsov, Heat transfer and physical dynamics, pp. 95-115 (Nauka, Moscow, 1974) [in Russian]

[9] D.A. Labuntsov, B.A. Kolchugin, V.S. Golovin, High Temp+, 2 (3), 446 (1964)

[10] L.E. Scriven, Chem. Engng. Sci., 10 (1/2), 1 (1959)

[11] Y.A Zeigarnik, K.A Hodak, Yu.L. Nizovskii, High Temp+, 47 (5), 707 (2009)

[12] M.E. Ellion, Jet prop. lab. Memo, pp. 20 - 88, CIT (1954)

[13] M. Plezet M., C. Zwick, Questions of the physics of boiling, pp. 189-211 (Mir, Moscow, 1964) [in Russian]

[14] Yu.A. Kuzma-Kichta, A.K. Ustinov, A.A. Ustinov, Proceedings of the $3 d$ Russian National Conference of Heat Transfer, Moscow, Russia, 2002 (MEI, Moscow, 2002), p. 127

[15] V.V. Kuznetsov, A.S. Shamirzaev, Microgravity Sci. Technol, 21, S305-S311 (2009)

[16] V.V. Kuznetsov, I.A. Kozulin, V.I. Oreshkin, A.S. Zhigalin, S.A. Chaikovsky, A.G Rousskikh, J Eng Thermophys-Rus, 20 (3), 240 (2011)

[17] V.V. Kuznetsov, E.S. Wasserman, Proceedings of the 6th Seminar "Acoustics of inhomogeneous media", Novosibirsk, Russia, 2000, pp. 56-60

[18] Yu.A. Zeigarnik, D.N. Platonov, K.A. Hodakov, Yu.L. Schechter, High Temp+ 49 (4), 584 (2011)

[19] Yu.A. Zeigarnik, I.V. Kirillova, A.I. Klimov, E.G. Smirnova, High Temp+ 20 (2), 303 (1983)

[20] Yu.A. Zeigarnik, High Temp+ 39 (3), 479 (2001)

[21] Yu.A. Zeigarnik, A.I. Klimov, A.G. Rotinov, B.A. Smyslov, Thermal Engineering 3, 14 (1997)

[22] V.S. Grigoriev, V.G. Zhilin, Yu.A. Zeigarnik, Yu.P. Ivochkin at el., High Temp+ 43 (1), 100 (2005)

[23] Yu.A. Zeigarnik, K.A. Hodakov, Yu.L. Schechter, High Temp+ 50 (3), 436 (2012)

[24] Yu.A. Zeigarnik, D.N. Platonov, K.A. Hodakov, Yu.L. Schechter, High Temp+ 50 (1), 83 (2012)

[25] V. Grishaev, A. Amirfazli, S. Chikov, Y. Lyulin, O. Kabov, Microgravity Sci. Technol. 25, 27 (2013)

[26] I. Marchuk, Y. Lyulin, O. Kabov, Interfacial Phenomena and Heat Transfer 1 (2), 153 (2013)

[27] O.N. Goncharova, M. Hennenberg, E.V. Rezanova, O.A. Kabov, Interfacial Phenomena and Heat Transfer 1 (4), 317 (2013)

[28] V. V. Cheverda, A. Glushchuk, P. Queeckers, S. B. Chikov, O. A. Kabov, Microgravity Sci. Technol. 25, 73 (2013) 